\title{
Comparison of Shoulder Neuromuscular Control in Overhead Athletes with and without Shoulder Hypermobility
}

\author{
Sungwoo Kang ${ }^{1,2} \mathrm{PhD}$, Kwanglae $\mathrm{Kim}^{3} \mathrm{PhD}$ \\ ${ }^{1}$ Graduate School of Sports and Leisure Studies, Korea National Sport University, Seoul; ${ }^{2}$ QOLFIT Training Center, Seoul; ${ }^{3}$ Department of Sports and Leisure Studies, \\ Hanyang Women's University, Seoul, Korea
}

\begin{abstract}
PURPOSE: A wider range of motion of shoulder joint is necessary for explosive throwing performance and the increase of the range of motion by repetitive throwing is inevitable. The wide range of motion is related with the instability of the joint. Neuromuscular control plays an essential role in stabilizing the joint. However, when the joint becomes hypermobile, how neuromuscular control was affected was not clear. The purpose of this study was to compare shoulder neuromuscular control of overhead shoulder athletes and identify the influence of hypermobility on it.
\end{abstract}

METHODS: Total 24 subjects (hypermobility group (HMG); 12 athletes, normal range group (CON); 12 athletes) were recruited in this research. To assess shoulder neuromuscular functions, joint position sense (JPS), the threshold of detection to passive motion (TTDPM), and force reproduction (FR) were measured.

RESULTS: In active JPS at HMG was greater than CON at the $90 \%$ target angle, $(p<.05)$. In passive JPS, HMG showed lower JPS compared to CON at the $50 \%$ target angle $(p<.05)$. In FR, HMG was lower than CON in internal rotation $(p<.05)$. In relationship test, hypermobility was negatively correlated with active JPS $(p<.05)$.

CONCLUSIONS: It was found that the hypermobile shoulder has greater neuromuscular control compared normal range shoulder to compensate for the hypermobility and active sub-system plays a crucial role in the neuromuscular control of the shoulder joint. Thus, it is recommended that neuromuscular training should be considered in training program for overhead athletes with hypermobile shoulder.

Key words: Shoulder hypermobility, Neuromuscular control, Joint position sense, Threshold to detection of passive motion, Force reproduction

\section{INTRODUCTION}

Shoulder joint plays an essential role in throwing performance. Wellcoordinated movements of many joints from lower extremities to upper extremities are required for the shoulder performance [1]. In overhead sports, shoulder joint is prone to be hypermobile by repetitive throwing motions with extreme range of motion [2]. The laxity of the joint that can potentially compromise joint stability can be increased $[3,4]$. Accordingly, during dynamic throwing motion, maintaining shoulder stability is very crucial to produce a greater throwing performance and to prevent injury risks at the wide end range where shoulder is extremely rotated externally $[2,5]$.

The shoulder functions can be influenced by motor abilities like flexibility, stability, strength, neuromuscular control. Above all, joint stability is considered to be fundamental for the other functions of the joint [6] Joint stabilizing systems consist of 3 sub-systems: passive, active, and neural control sub-systems $[7,8]$. The passive sub-system provides static joint stability and capsule-ligamentous structures are included in the system. When capsule or ligament is lax, the ability to mechanically support the joint is decreased and it also causes decrease of afferent infor-

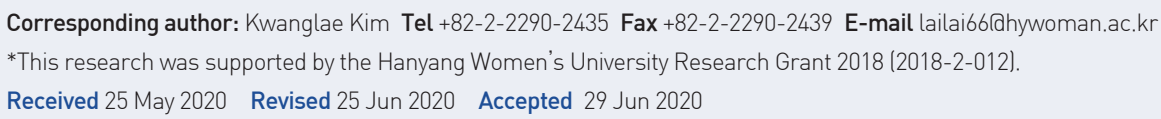


mation of the joint that is transferred to central nervous system (CNS) $[9,10]$. Active sub-system, including muscles and tendons, is responsible for efficiently producing force and tension for stabilizing trunk and upper extremity [7,11]. Lastly, neural control sub-system provides a considerable interaction between active sub-system and passive sub-system to stabilize the joint [12]. Particularly, in dynamic movement like throwing, neuromuscular control by CNS plays a crucial role in generating appropriate muscle activation to stabilize shoulder joint and produce explosive movements [8].

It has been reported that overthrowing athletes tend to have excessive external rotation of shoulder [2]. The wide range is correlated with greater arm cocking and faster throwing velocity during throwing motion [13]. However, the acquired hypermobility is also considered as the risk of shoulder overuse injuries [14]. It is called as thrower's paradox that throwing shoulder needs to be mobile and stable simultaneously for maintaining explosive throwing performance and avoiding injury [15].

On the other hand, other researches insisted that the repetitive overhead motions enhance proprioceptive ability of shoulder joint because the repetitive motions near the end range of the joint increase a simulation of muscle spindles in muscles and mechanoreceptors in capsules and ligaments around the joint that is required for joint stabilization $[15,16]$. However, it is unclear effects of overthrowing with wide range of shoulder motion on neuromuscular function of the joint for throwing performance and injury prevention.

Thus, this study aimed to compare shoulder neuromuscular responses of overthrowing athletes with and without shoulder hypermobility and to identify the influence of hypermobility on neuromuscular response of shoulder joint.

\section{METHODS}

\section{Participants}

Total 24 overthrowing athletes (13 handball athletes and 11 javelins) were recruited and it comprised 16 male and 8 female athletes. The subjects were divided into the 2 groups (hypermobility group [HMG]; 12 athletes, normal range group [CON]; 12 athletes) in this research (Table 1). The active shoulder external rotation was measured. When the external rotation was over $90^{\circ}$, the participant was allocated in $\mathrm{HMG}$ and if less than $90^{\circ}$ of the rotation, the athlete was allocated in CON [17]. A participant who had a problem on shoulder joint of throwing side and cardiovascular function for last 6 months before this study was excluded
Table 1. The characteristics of the subjects in the study

\begin{tabular}{lccc}
\hline & HMG & CON & $p$-value \\
\hline Age $(\mathrm{yr})$ & $19.00 \pm 0.74^{*}$ & $20.17 \pm 1.47$ & .025 \\
Height $(\mathrm{cm})$ & $179.84 \pm 8.97$ & $174.27 \pm 8.32$ & .129 \\
Weight $(\mathrm{kg})$ & $84.17 \pm 16.63$ & $80.13 \pm 9.88$ & .478 \\
BMI $\left(\mathrm{kg} / \mathrm{m}^{2}\right)$ & $25.16 \pm 2.48$ & $26.39 \pm 2.90$ & .275 \\
Career $(\mathrm{yr})$ & $7.92 \pm 2.02$ & $8.92 \pm 3.78$ & .427
\end{tabular}

Values are presented as mean \pm standard deviation.

HMG, hypermobility group; CON, normal range group.

${ }^{*} \mathrm{HMG}$ vs. NMG; ${ }^{*} p<.05$.

from this study. All subjects were informed of the potential risks associated with this experiment before the test. This study was reviewed and approved by the committee on research ethics of Korea National Sport University before all the procedures began.

\section{Measurements Procedure}

\section{1) Procedure}

To measure neuromuscular function of shoulder joint in dominant throwing arm, active-and passive-joint position sense (JPS), threshold to detection of passive motion (TTDPM), and force-reproduction (FR) were evaluated in this study. To avoid test errors by muscle fatigue from trials, the order of the tests was as follow; (1) range of motion, (2) AJPS, (3) PJPS, (4) TTDPM, and (5) FR. All tests were performed in shoulder of dominant throwing arm and conducted by same researcher for reliability of test. Isokinetic dynamometer (CSMi, HUMAC, USA) was used for assessing them.

\section{2) Shoulder range of motion (ROM)}

In assessment of active ROM of shoulder joint, internal rotation (IR), external rotation (ER), and total range of motion (sum of IR and ER) were measured. The active ROM of shoulder girdle was measured on supine position with $90^{\circ}$ of shoulder abduction and $90^{\circ}$ of elbow flexion. When the subjects felt the end feel during shoulder motion, the range was determined as active shoulder range of motion. Two trials were carried out and the average of the results of the measurements was used for the value of range of motion of shoulder joint.

\section{3) Joint position sense}

Joint position sense was performed to assess an ability to detect a joint position. Active joint position sense (AJPS) measurement was conducted in the position with $90^{\circ}$ of shoulder abduction and $90^{\circ}$ of elbow flexion in supine position. In this study, the target angles were set at 50\% angle 
of the full external rotation and at 90\% angle of the end range of external rotation, where joint mechanoreceptors are best stimulated [18]. First, the subject was held at the target angle for 5 seconds by the instructor and then asked to memorize it. After returning to the start position, the subject was instructed to reproduce the target angle and to say "STOP" when they feel the joint is reached at the target angle [19]. Passive joint position sense (PJPS) was also assessed on same position with AJPS [18]. The subject was only instructed to passively replicate the target angles. The $2 \%$ sec velocity of passive movement was used in PJPS. Total 3 tests were performed after 2 practices and 10 seconds were provided between trials for rest in AJPS and PJPS assessments. Error angles between target angle and reproduced angle were recorded as the value of the tests. The average of 3 error angles was recorded for the result of the measurement. Each participant wore blindfold, headset with white noise and pneumatic sleeve to eliminate visual, auditory and tactile afferent information from the measurement device [20].

\section{4) Threshold To detection of passive motion}

TTDPM is a method to evaluate an ability to sense a slow passive motion of joint. TTDPM was also assessed on same position with JPS and on internal- and external rotations. The velocity of the passive motion was set at $0.2 \% \mathrm{sec}$. The test arm of the subject was passively moved to the start position, at $45 \%$ angle of the range of external rotation and the subject was asked to say "STOP" as soon as it perceived the passive motion. 2 practice trials and 5 tests, and 10 seconds break for rest among the trials were provided [21]. The displacement between the starting angle and the perceived angle was recorded for the result of the trial. The average of the 5 results was recorded for the result of the measurement [22]. In TTDPM, blindfold, headset and pneumatic sleeve were used to eliminate the afferent information [20].

\section{5) Force-reproduction}

FR was carried out to assess the ability to sense tension or force produced in a joint [23]. FR test was performed in standing position with $45^{\circ}$ of shoulder abduction in the scapular plane and $90^{\circ}$ of elbow flexion. Firstly, maximum voluntary isometric contraction (MVIC) of internal rotation of shoulder was measured. 3 measurements of MVIC were conducted and $50 \%$ of the highest MVIC was used for the target force to reproduce $[18,23]$. For FR test, we instructed the subjects to maintain $50 \%$ torque of their highest MVIC in shoulder IR for 3 seconds. to perceive the force. Participants were asked to replicate the target force for 3 secconds. and to express verbal sign, 'stop' when they perceived the target rotational moment. Before testing, visual and audible feedbacks were removed by blindfold and headset. The subjects had 2 practices and 3 measurement trials. 10 seconds break time between trials was provided for resting. The force difference between the target force and reproduced force was calculated at each trial and the average of the measured forces was determined for the test results [22].

\section{Statistical Analysis}

The data was analyzed by SPSS program (version 18, SPSS INC, Chicago, IL). All values were presented as mean and standard deviation (mean $\pm \mathrm{SD}$ ). Independent $t$-test was performed to compare AJPS, PJPS TTDPM, and FR of hypermobility group and normal range group. Pearson correlation analysis was used to analyze a relationship between hypermobility and neuromuscular responses in the throwing shoulder joint. The relationship's strength was identified follow as; $0.00-0.25=$ little or no; 0.26-0.50 = fair; 0.51- $0.75=$ moderate to good; $0.76-1.00=$ good to excel lent. Statistic level of less than 0.05 was considered significant.

\section{RESULTS}

\section{Shoulder range of motion}

In shoulder ROM, hyper-mobility group HMG significantly demonstrated greater compared to normal range group $(\mathrm{CON})$ in external rotation $\left[\mathrm{HMG}\left(102.83^{\circ} \pm 7.61\right)\right.$ vs. $\left.\mathrm{CON}\left(74.17^{\circ} \pm 4.02^{\circ}\right), p=.000\right]$ and total range of motion $\left[\mathrm{HMG}\left(161.83^{\circ} \pm 18.33^{\circ}\right)\right.$ vs. CON $\left(130.42^{\circ} \pm 7.77^{\circ}\right)$ $p=.000]$. There was no significant difference between HMG and CON in internal rotation of shoulder $\left[\mathrm{HMG}\left(59.00^{\circ} \pm 13.06^{\circ}\right)\right.$ vs. $\mathrm{CON}\left(56.25^{\circ}\right.$ $\left.\left.\pm 7.30^{\circ}\right), p=.637\right]$ (Fig. 1).

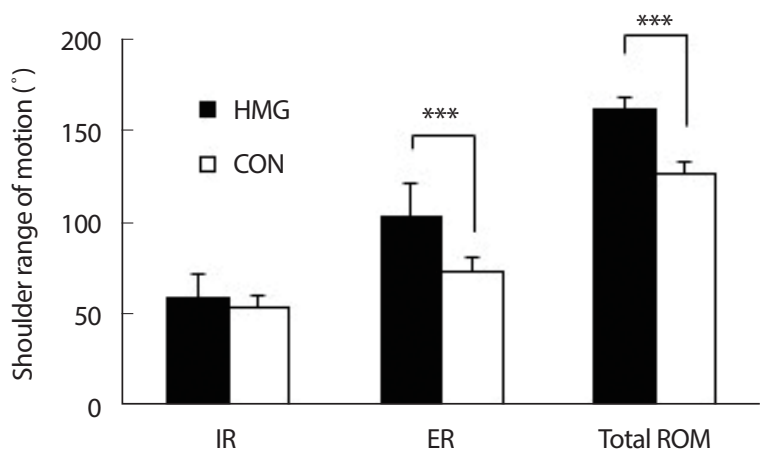

Fig. 1. Range of motion (ROM) of shoulder joint in the groups. HMG; hypermobility group; CON, normal range group; IR, internal rotation; ER, external rotation; Total ROM, total range of motion. ${ }^{*} \mathrm{HMG}$ vs. $\mathrm{CON}$; ${ }^{* * *} p<.001$. 
Table 2. JPS, TTDPM and FR of shoulder joint in the groups

\begin{tabular}{|c|c|c|c|c|c|}
\hline Variable & & roup & HMG & CON & $p$-value \\
\hline \multirow{4}{*}{$\begin{array}{l}\text { Joint position } \\
\text { sense }\end{array}$} & AJPS & $50 \%$ & $6.44 \pm 3.43$ & $4.22 \pm 2.29$ & .075 \\
\hline & (degree) & $90 \%$ & $4.67 \pm 1.71^{*}$ & $7.89 \pm 4.72$ & $\begin{array}{c}\mathrm{HMG}<\mathrm{CON} \\
(.043)\end{array}$ \\
\hline & $\begin{array}{c}\text { PJPS } \\
\text { (degree) }\end{array}$ & $50 \%$ & $10.36 \pm 5.39^{*}$ & $6.33 \pm 2.76$ & $\begin{array}{c}\mathrm{HMG}>\mathrm{CON} \\
(.035)\end{array}$ \\
\hline & & $90 \%$ & $9.61 \pm 4.41$ & $8.44 \pm 4.99$ & .550 \\
\hline TTDPM & $\begin{array}{c}\text { ER } \\
\text { (degree) }\end{array}$ & & $1.30 \pm 1.29$ & $0.88 \pm 0.67$ & .321 \\
\hline $\begin{array}{l}\text { Force } \\
\text { reproduction }\end{array}$ & $\begin{array}{c}\text { IR } \\
(\mathrm{N} / \mathrm{m})\end{array}$ & & $3.79 \pm 1.50^{*}$ & $2.25 \pm 1.28$ & $\begin{array}{c}\mathrm{HMG}>\mathrm{CON} \\
(.013)\end{array}$ \\
\hline
\end{tabular}

Values are presented as mean \pm standard deviation.

HMG, hypermobility group; CON, normal range group; IR, internal rotation; ER, external rotation; AJPS, active joint position sense; PJPS, passive joint position sense; TTDPM, threshold to detection of passive motion.

${ }^{*} \mathrm{HMG}$ vs. NMG; ${ }^{*} p<0.05$.

\section{Joint position sense}

JPS was assessed at the 50\% and 90\% angles of the range of shoulder external rotation. In AJPS, hyper-mobility group showed less error angles than control group at the $90 \%$ target angle, $(p=.043)$. On the other hand, at the 50\% target angle, it was shown that there was no significant difference between the both groups in AJPS ( $p=.075)$. In PJPS, no significant difference between $\mathrm{HMG}$ and $\mathrm{CON}$ at the $90 \%$ target angle was appeared $(p=.055)$. However, at the 50\% target angle, hypermobility group showed greater error angles compared to normal range group in PJPS $(p=.035)$ (Table 2).

\section{Threshold to detection of passive motion}

TTDPM was also evaluated at the $45 \%$ of the range of external rotation to perceive passive motion of shoulder joint. The result showed there was no significant difference between HMG and CON in TTDPM to detect passive external rotation of the joint $(p=.321)$ (Table 2).

\section{Force reproduction}

In this study, force reproduction test was performed to evaluate an ability of mechanical feedback of muscles around shoulder joint. The result was shown that the force reproduction ability of HMG was lower than that of CON in internal rotation $(p=.013)$ (Table 2).

\section{Hypermobility and neuromuscular control}

Hypermobility seemed to be negatively related with error angles of AJPS at the $90 \%$ target angle $(r=-0.416, p=.043)$ (Fig. 2). However, there was no significant relationship between hypermobility and error passive

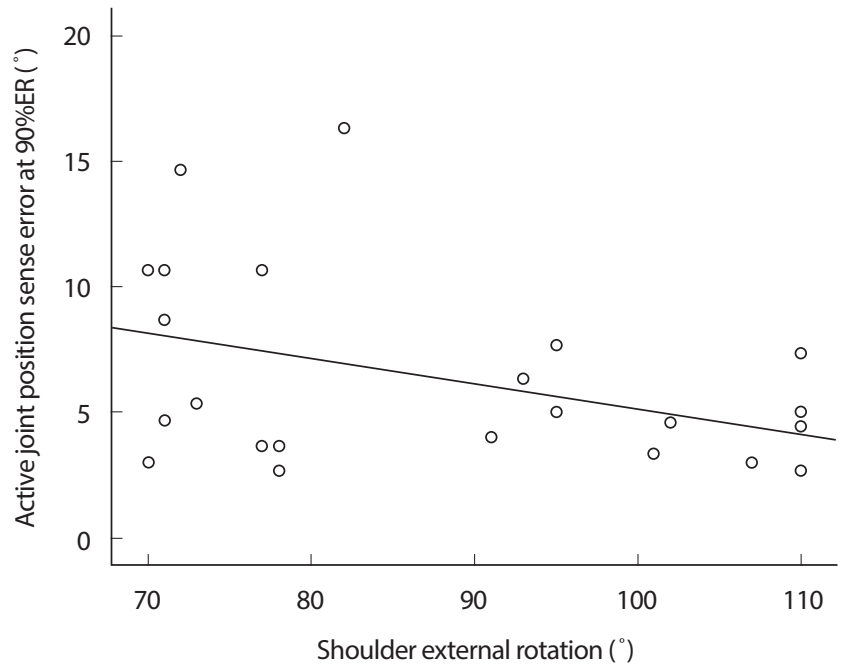

Fig. 2. Relationship between shoulder external rotation and active joint position sense.

joint position sense (at 90\%ER, $r=.052, p=.811$; at 50\%ER, $r=.298$, $p=.157)$. Hypermobility was also positively correlated with force production (FR) ability in internal rotation $(r=.533, p=.007)$. Relationships between hypermobility and TTDPM was not significant $(r=.260, p=.220)$.

\section{DISCUSSION}

The purpose of this study was to identify relationship between joint hypermobility and neuromuscular control of throwing shoulder. Shoulder joint plays a key role in throwing performance in the sports such as baseball, volleyball, handball, and javelin [1]. Muscle strength, flexibility, stability, and power are required for the explosive motion [6]. However, repetitive throwing motions in games and practices can make a shoulder joint lax and hypermobile. As a result, it causes instability of the joint [3]. The stability should be maintained for throwing performance and injury prevention during the dynamic motions [5]. A neuromuscular control is necessary for a joint stabilization in the wide range of motion [16].

In this research, HMG showed greater external range of motion in shoulder joint compared to normal range group (CON). Generally, a range of motion of throwing shoulder tends to be greater than the range of non-throwing side and it is usually referred to as ERG [15]. In previous studies, it has been reported that in overhead sports, a hypermobility of the dominant throwing shoulder has been steadily observed [24] However, the fact is controversial for years whether the acquired joint motion is required for throwing performance or needed to be controlled for preventing an injury $[13,14]$. Some researchers have insisted that 
maintaining the stability in the wide range is important for the both goals during dynamic motion like overhead throwing [25]. Joint stability is determined by a mount of stiffness of soft tissues such as capsules, and ligaments and neuromuscular function $[7,8]$. Hence, in this study, joint position sense TTDPM, and force reproduction (FR) were measured to identify neuromuscular function of shoulder joint.

JPS is the neuromuscular function to detect joint positions and JPS can be conducted in active and passive modes [19]. AJPS is to evaluate an ability to perceive joint positons during dynamic motion [20]. Dynamic stabilization system, like active joint position, is a key function to stabilize and control a joint during mid-range of joint motion [26].

In AJPS test, HMG group showed higher joint position sense than CON group. The result observed is consistent with other researches reporting that hypermobile joint groups or subjects are inclined to have greater neuromuscular functions compared to normal range groups $[27,28]$. In the correlation between hypermobility and neuromuscular function, it was also found that hypermobility was natively related with errors of active joint position sense. It means that the more hypermobile shoulder is inclined to have greater neuromuscular function in overhead throwing athletes. For explosive throwing performance, overhead athletes require a sufficient range of motion of shoulder joint where can efficiently produce greater force from stretched muscles of shoulder joint in terms of length-force relationship [29] and simultaneously, joint stability needs to be controlled within the wide range during the explosive overhead motion [23].

Additionally, when the joint is approached to the end range of joint motion during throwing, mechanoreceptors in muscles, capsules, ligaments, and fascia are stimulated [10], overhead athletes are able to take advantage of greater stretch-shortening cycle (SSC) reflexively produced by the stretch-induced stimulation for power production. In addition, at the end range, afferent input transferred to CNS for controlling the joint is also increased [30]. Hence, in overhead sports, neuromuscular control of hypermobile shoulder should be well-trained and adapted to the dynamic throwing motion for better performance and injury prevention during the wide range of motion.

However, HMG group showed greater joint position errors than $\mathrm{CON}$ group in PJPS that in passive mode. It means neuromuscular function of hypermobility group is lower than normal range group in passive mode to assess mainly proprioceptors stimulated passively [19]. This finding results from the effects of increased joint laxity acquired from repetitive throwing motions.
TTDPM, greater errors in HMG group were found compared to CON group, although there was no significant difference between the both groups. Furthermore, in the correlation analysis, hypermobility was negatively related with passive joint position sense at $50 \%$ target angle where muscles around the joint are relatively less stretched and loose. The results can be explained by changes of the afferent information discharged from mechanoreceptors of the shoulder joint [31].

Joint laxity is mainly determined by passive sub-system like joint capsule and ligaments [7,32]. Since the capsule-ligamentous structures are loosened, joint laxity is increased and then the joint is able to be hypermobile and instable [33]. A tension in the loosened tissues is decreased and then the afferent information transferred to central nervous system is also reduced [34]. As a result, decreased neuromuscular function such as joint position sense and kinesthesia of shoulder joint from the laxity causes joint instability during the dynamic motion [35]. Due to the aforementioned reasons, in overhead throwing athletes with shoulder hypermobility, shoulder muscles like rotator cuff, play an important role in actively controlling the joint stability during wide range motion [36]. Therefore, neuromuscular training should also be included in the training program for overhead sports athletes who have hypermobile shoulder with strengthening muscles [37].

FR test was used to evaluate an ability to regenerate the muscle force that the subjects produced before $[18,23]$. FR test is known as a modality to assess the sense of tension that comes from mechanoreceptors embedded in muscles [38]. When muscles around joint are stretched near the end range of the motion, activation of muscle spindles and additional tension from ligaments and capsular structures of joint are increased for dynamic stabilization of joint [31]. It is helpful for detecting a sense of force and tension of the joint [39].

In the FR test of this study, the force reproduction ability of HMG group was lower than $\mathrm{CON}$ group. It means that a change of muscle stiffness alters amount of afferent information from the muscle spindle and joint mechanoreceptors. The alteration of the proprioceptive information affects the ability to sense force produced at the target joint angles [40].

The results of the FR test can be explained by the change of muscle stiffness. It is influenced by the testing position, 45 degrees of shoulder abduction in scapular plane. At the position, the anterior muscles of the shoulder joint of HMG group were relatively less stretched and loose compared to $\mathrm{CON}$ group. The decreased tensions by the loose muscles can affect a detection of the muscle sense produced in the joint. In previ- 
ous study, it was reported that a difference of muscle tension influences on the ability to detect tension by muscles of joint [23]. Thus, to accurately measure the ability to sense a tension and force of joint, the ability is need to be assessed at various joint angles or muscle lengths [41].

As a result, the wide range motion of shoulder joint, especially in external rotation, is inevitable and natural phenomenon for throwing performance. To get the wide range of shoulder, the shoulder joint should be flexible and stable for explosive movement. Thus, muscle function and neural control are important for maintaining stability of shoulder joint for throwing athletes. In this study, it was found that hypermobile joint group has greater neuromuscular function controlled by active subsystem than normal range group but in passive motion, neural function of hypermobility group was lower compared to normal range group. It means active sub-system like muscle plays a more crucial role in neuromuscular function of shoulder joint in the dynamic overhead throwing. Neuro-muscular functions like sensitivity or reflexive response of muscles around throwing shoulder should be considered and included in training and conditioning program for throwing performance and joint stability of overhead throwing athletes.

However, in this study, measurements about throwing performance were not conducted. So it is unclear how difference of neuromuscular control in shoulder joint influences on throwing performance. In the future research, the research that identifies influences of neuromuscular function on throwing performance in overhead athletes with hypermobility will be needed. Also, small number of overthrowing athletes were recruited in this study. The numbers would be not enough to clearly identify the effect of shoulder hypermobility on neuromuscular control of the overhead throwing joint. Future research should therefore be conducted by greater number of overhead athletes.

In conclusion, throwing shoulder should be mobile to throw it explosively and stable to prevent an injury from repetitive overhead motions. The present study investigated the influence of the shoulder hypermobility on neuromuscular control in overhead athletes. It was found that the hypermobile shoulder has greater neuromuscular function than normal range group in dynamic motion test. It means the greater neuromuscular control in hypermobile shoulder is appeared to compensate for the hypermobility and active sub-system like muscle, plays a crucial role in the neuromuscular control of the shoulder joint. Thus, it is recommended that neuromuscular training should be considered in training program for overhead athletes with hypermobile shoulder. Future studies on relationship among hypermobility, neuromuscular control, and throwing performance will be informative to improve a throwing performance and prevent a shoulder injury.

\section{ORCID}

Sungwoo Kang https://orcid.org/0000-0003-34588343

Kwanglae Kim https://orcid.org/0000-0002-0210-2532

\section{CONFLICT OF INTEREST}

No potential conflict of interest relevant to this article was reported.

\section{ACKNOWLEDGEMENTS}

The author appreciates the subjects for participating in this study. This research was supported by the Hanyang Women's University Research Grant 2018 (2018-2-012).

\section{AUTHOR CONTRIBUTIONS}

Conceptualization: SWK, KLK; Data curation: SWK; Formal analysis: SWK; Funding acquisition: KLK; Methodology: SWK, KLK; Project administration: SWK, KLK; Visualization: SWK; Writing-original draft: SWK, KLK; Writing-review \& editing: SWK, KLK.

\section{REFERENCES}

1. van den Tillaar R, Ettema G. Influence of instruction on velocity and accuracy of overarm throwing. Percept Mot Skills. 2003;96(2):423-34.

2. Wassinger CA, Myers JB, Gatti JM, Conley KM, Lephart SM. Proprioception and throwing accuracy in the dominant shoulder after cryotherapy. J Athl Train. 2007;42(1):84-9.

3. Cameron KL, Duffey ML, DeBerardino TM, et al. Association of generalized joint hypermobility with a history of glenohumeral joint instability. J Athl Train. 2010;45(3):253-8.

4. Harryman DT II, Sidles JA, Clark JM, McQuade KJ, Gibb TD, et al. Translation of the humeral head on the glenoid with passive glenohumeral motion. J Bone Joint Surg Am. 1990;72(9):1334-43.

5. Andrade MS, de Carvalho Koffes F, Benedito-Silva AA, da Silva AC, de Lira CAB. Effect of fatigue caused by a simulated handball game on ball throwing velocity, shoulder muscle strength and balance ratio: a 
prospective study. BMC Sports Sci Med Rehabil. 2016;8:13.

6. Dale RB, Kovaleski JE, Ogletree T, Heitman RJ, Norrell PM. The effects of repetitive overhead throwing on shoulder rotator isokinetic work-fatigue. N Am J Sports Phys Ther. 2007;29(2):74-80.

7. Hess SA. Functional stability of the glenohumeral joint. Man Ther. 2000;5(2):63-71.

8. Panjabi M. The Stabilizing system of the spine. Part 1. Function, dysfunction, adaption and enhancement. J Spinal Disord. 1992;5(4):383-9.

9. Lephart SM, Pincivero DM, Giraldo JL, Fu FH. The role of proprioception in the management and rehabilitation of athletic injuries. Am J Sports Med. 1997;25(1):130-7.

10. Rajaratnam BS, Goh CH, Kumar PV. Control strategies to re-establish glenohumeral stability after shoulder injury. BMC Sports Sci Med Rehabil. 2013;5(1):26.

11. Wilkin LD, Haddock BL. Isokinetic strength of collegiate baseball pitchers during a season. J Strength Cond Res. 2006;20(4):829-32.

12. Myers JB, Lephart SM. The role of the sensorimotor system in the athletic shoulder. J Athl Train. 2000;35(3):351-63.

13. Ellenbecker TS, Roetert EP, Bailie DS, Davies GJ, Brown SW. Glenohumeral joint total rotation range of motion in elite tennis players and baseball pitchers. Med Sci Sports Exerc. 2002;34(12):2052-6.

14. Borsa PA, Laudner KG, Sauers EL. Mobility and stability adaptations in the shoulder of the overhead athlete: a theoretical and evidencebased perspective. Sports Med. 2008;38(1):17-36.

15. Wilk KE, Meister K, Andrews IR. Current concepts in the rehabilitation of the overhead throwing athlete. Am J Sports Med. 2002;30(1): $136-51$.

16. Swanik KA, Lephart SM, Swanik CB, Lephart SP, Stone DA, et al. The effects of shoulder plyometric training on proprioception and selected muscle performance characteristics. J Shoulder Elbow Surg. 2002; 11(6):579-86.

17. Norkin CC, White DJ. Measurement of joint motion: a guide to goniometry. FA Davis; 2016 Nove 18.

18. Dover G, Powers ME. Reliability of joint position sense and force-reproduction measures during internal and external rotation of the shoulder. J Athl Train. 2003;38(4):304-10.

19. Myers JB, Guskiewicz KM, Schneider RA, et al. Proprioception and neuromuscular control of the shoulder after muscle fatigue. J Athl Train. 1999;34(4):362-7.

20. Riemann BL, Myers JB, Lephart SM. Sensorimotor system measurement techniques. J Athl Train. 2002;37(1):85-98.
21. Benjaminse A, Sell TC, Abt JP, House AJ, Lephart SM. Reliability and precision of hip proprioception methods in healthy individuals. Clin J of Sport Med. 2009;19(6):457-63.

22. Deshpande N, Connelly DM, Culham EG, Costigan PA. Reliability and validity of ankle proprioceptive measures. Arch Phys Med Rehabil. 2003;84(6):883-9.

23. Maenhout AG, Palmans T, De Muynck M, De Wilde LF, Cools AM. The impact of rotator cuff tendinopathy on proprioception, measuring force sensation. J Sh-oulder Elbow Surg. 2012;21(8):1080-6.

24. Borsa PA, Dover GC, Wilk KE, Reinold MM. Glenohumeral range of motion and stiffness in professional baseball pitchers. Med Sci Sports Exerc. 2006;38(1):21-6.

25. Cools AM, Borms D, Castelein B, Vanderstukken F, Johansson FR. Evidence-based rehabilitation of athletes with glenohumeral instability Knee Surg Sports Traumatol Arthrosc. 2016;24(2):382-9.

26. Wuelker N, Korell M, Thren K. Dynamic glenohumeral joint stability. J Shoulder Elbow Surg. 1998;7(1):43-52.

27. Folland JP, Buckthorpe MW, Hannah R. Human capacity for explosive force production: neural and contractile determinants. Scand J Med Sci Sports. 2014;24(6):894-906.

28. Jensen BR, Sandfeld J, Melcher PS, Johansen KL, Hendriksen P, et al. Alterations in neuromuscular function in girls with generalized joint hypermobility. BMC Musculoskelet Disord. 2016;17(1):410.

29. Gordon AM, Huxley AF, Julian FJ. The variation in isometric tension with sarcomere length in vertebrate muscle fibres. J Physiol. 1966; 184(1):170-92

30. Moraes MR, Cavalcante ML, Leite JA, Macedo JN, Sampaio ML, et al. The characteristics of the mechanoreceptors of the hip with arthrosis. J Orthop Surg. Res. 2011;6:58.

31. Coskun G, Talu B, Cools A. Proprioceptive force-reproduction of the rotator cuff in healthy subjects before and after muscle fatigue. Isokinet Exerc Sci. 2018;26(3):1-7.

32. Altchek DW, Warren RF, Skyhar MJ, Ortiz G. T-plasty modification of the bankart procedure for multidirectional instability of the anterior and inferior types. J Bone Joint Surg Am. 1991;73(1):105-12.

33. Dewing CB, McCormick F, Bell SJ, Solomon DJ, Stanley M, et al. An analysis of capsular area in patients with anterior, posterior, and multidirectional shoulder instability. Am J Sports Med. 2008;36(3):515-22.

34. Merolla G, Cerciello S, Chillemi C, et al. Multidirectional instability of the shoulder: biomechanics, clinical presentation, and treatment strategies. Eur J Orthop Surg Traumatol. 2015;25(6):975-85. 
35. Barden JM, Balyk R, Raso VJ, Moreau M, Bagnall K. Dynamic upper limb proprioception in multidirectional shoulder instability. Clin Orthop Relat Res. 2004;420:181-9.

36. Mallon WJ, Speer KP. Multidirectional instability: current concepts. J Shoulder Elbow Surg. 1995;4(1):54-64.

37. Guerrero P, Busconi B, Deangelis N, Powers G. Congenital instability of the shoulder joint: assessment and treatment options. J Orthop Sports Phys Ther. 2009;39(2):124-34.

38. Allison KF, Sell TC, Benjaminse A, Lephart SM. Force sense of the knee not affected by fatiguing the knee extensors and flexors. J Sport
Rehabil. 2016;25(2):155-63.

39. Janwantanakul P, Magarey ME, Jones MA, Dansie BR. Variation in shoulder position sense at mid and extreme range of motion. Arch Phys Med Rehabil. 2001;82(6):840-4.

40. Kaynak H, Altun M, Tok S. Effect of force sense to active joint position sense and relationships between active joint position sense, force sense, jumping and muscle strength. J Mot Behav. 2020;52(3):342-51.

41. Cafarelli E, Bigland-Ritchie B. Sensation of static force in muscles of different length. Exp Neurol. 1979;65(3):511-25. 